\title{
Inhalational anthrax(Ames aerosol) in naïve and vaccinated New Zealand rabbits: characterizing the spread of bacteria from lung deposition to bacteremia
}

\author{
Bradford W. Gutting ${ }^{1 *}$, Tonya L. Nichols ${ }^{2}$, Stephen R. Channel ${ }^{3}$, Jeffery M. Gearhart ${ }^{4}$, \\ George A. Andrews ${ }^{1}$, Alan E. Berger ${ }^{1}$, Ryan S. Mackie ${ }^{1}$, Brent J. Watson ${ }^{1}$, Sarah C. Taft ${ }^{2}$, \\ Katie A. Overheim ${ }^{5}$ and Robert L. Sherwood ${ }^{5}$
}

${ }^{1}$ Naval Surface Warfare Center (Dahlgren Division), Dahlgren, VA, USA

2 Environmental Protection Agency, Cincinnati, OH, USA

${ }^{3}$ Defense Threat Reduction Agency, Edgewood, MD, USA

${ }^{4}$ Wright-Patterson Air Force Base, Dayton, OH, USA

${ }^{5}$ Lovelace Respiratory Research Institute, Albuquerque, NM, USA

\section{Edited by:}

Margaret Louise Mansel Pitt,

United States Army Medical

Research Institute of Infectious

Diseases, USA

Reviewed by:

Christopher Cote, United States Army Research Institute of

Infectious Diseases, USA

James Estep, Battelle Memorial

Institute, USA

*Correspondence:

Bradford W. Gutting, Naval Surface Warfare Center (Dahlgren Division), CBR Concepts and Experimentation Branch, Dahlgren, 4045 Higley

Road, Suite 345, Dahlgren,

VA 22448-5162, USA.

e-mail:dlgr_nswc_z20@navy.mil
There is a need to better understand inhalational anthrax in relevant animal models. This understanding could aid risk assessment, help define therapeutic windows, and provide a better understanding of disease. The aim here was to characterize and quantify bacterial deposition and dissemination in rabbits following exposure to single high aerosol dose (>100 LD 50 ) of Bacillus anthracis (Ames) spores immediately following exposure through $36 \mathrm{~h}$. The primary goal of collecting the data was to support investigators in developing computational models of inhalational anthrax disease. Rabbits were vaccinated prior to exposure with the human vaccine (Anthrax Vaccine Adsorbed, AVA) or were sham-vaccinated, and were then exposed in pairs (one sham and one AVA) so disease kinetics could be characterized in equally-dosed hosts where one group is fully protected and is able to clear the infection (AVA-vaccinated), while the other is susceptible to disease, in which case the bacteria are able to escape containment and replicate uncontrolled (sham-vaccinated rabbits). Between $4-5 \%$ of the presented aerosol dose was retained in the lung of sham- and AVA-vaccinated rabbits as measured by dilution plate analysis of homogenized lung tissue or bronchoalveolar lavage (BAL) fluid. After 6 and $36 \mathrm{~h}$, $>80 \%$ and $>96 \%$, respectively, of the deposited spores were no longer detected in $\mathrm{BAL}$, with no detectable difference between sham- or AVA-vaccinated rabbits. Thereafter, differences between the two groups became noticeable. In sham-vaccinated rabbits the bacteria were detected in the tracheobronchial lymph nodes (TBLN) $12 \mathrm{~h}$ post-exposure and in the circulation at $24 \mathrm{~h}$, a time point which was also associated with dramatic increases in vegetative CFU in the lung tissue of some animals. In all sham-vaccinated rabbits, bacteria increased in both TBLN and blood through $36 \mathrm{~h}$ at which point in time some rabbits succumbed to disease. In contrast, AVA-vaccinated rabbits showed small numbers of CFU in TBLN between 24 and $36 \mathrm{~h}$ post-exposure with small numbers of bacteria in the circulation only at $24 \mathrm{~h}$ post-exposure. These results characterize and quantify disease progression in naive rabbits following aerosol administration of Ames spores which may be useful in a number of different research applications, including developing quantitative models of infection for use in human inhalational anthrax risk assessment.

Keywords: inhalational, anthrax, Ames, rabbit, deposition, lung, lymph, blood

\section{INTRODUCTION}

Anthrax is an infectious disease caused by Bacillus anthracis, a gram-positive, non-motile, spore-forming bacterium (Brachman et al., 1960; Dixon et al., 1999; Grinberg et al., 2001; Mock and Fouet, 2001; Frazier et al., 2006). In humans, exposure results from contact, ingestion or inhalation of spores leading to three distinct clinical diseases: cutaneous, gastrointestinal, and inhalational, respectively. Inhalational anthrax is the most lethal form of the disease and exposure to respirable spores has been a longstanding concern in biodefense (Frazier et al., 2006). Indeed, the ability of $B$. anthracis to induce morbidity and mortality as a bioweapon was demonstrated in the fall of 2001 when spore-laced letters were sent through the US mail system causing five inhalational anthrax fatalities (Dewan et al., 2002; 
Jernigan et al., 2002; Holtz et al., 2003). Today, B. anthracis may represent the single greatest biological warfare threat (Cleret et al., 2007).

Two important components in successfully protecting people are to better define the risk of disease in man and to develop effective therapeutics (Inglesby et al., 1999, 2002; Canter, 2005; Yee et al., 2010). However, because naturally occurring inhalational anthrax in man is exceptionally rare and therefore the data describing human inhalational anthrax disease is limited, work toward meeting these two goals must rely heavily on information obtained from relevant inhalational anthrax animal models (Hambleton et al., 1994; Watson and Keir, 1994; Frazier et al., 2006; see also FDA two-animal rule- 21 C.F.R. $\$ 314.610$, drugs; $\$ 601.91$, biologics). Here, the rabbit and non-human primate are often cited as the most appropriate animal models for use in generating data relevant to human inhalational anthrax, at least from a perspective of testing therapeutics or comparing pathological lesions during the end stage of disease. Thus, research that advances our quantitative understanding of inhalational anthrax in the rabbit will contribute to a better understanding of disease and help decision makers prepare in defense against future attacks.

A leading hypothesis in disease initiation and spread suggests inhaled spores are deposited in the conducting airways where they are quickly phagocytosed by alveolar macrophages (Ross, 1957; Dixon et al., 1999; Guidi-Rontani et al., 1999; Guidi-Rontani, 2002). The spores are then transported to the draining lymph nodes due to the migratory capacity of the alveolar macrophage. It is thought that spores germinate inside the macrophages either en route to the lymph node or immediately after reaching the lymph node (Dixon et al., 1999; Guidi-Rontani et al., 1999; Guidi-Rontani, 2002; Ireland and Hanna, 2002). Germination is associated with lethal toxin and edema toxin production that enable the bacteria to escape from the macrophage and enter a significant growth phase extracellular to host immune cells (Loving et al., 2009). Bacteria then spread via the efferent lymph system, and are eventually released into the blood at the thoracic duct. Bacterial replication in the circulation quickly follows and at the time of death bacterial levels can reach $10^{10}$ bacteria/ml blood. Although much data has been collected in support of this hypothesis, other work suggests alternative pathogenesis pathways may be involved. For example, deposited spores may interact with dendritic cells or epithelial cells during the early stages of disease (Shetron-Rama et al., 2010; Weiner and Glomski, 2012).

Although the research cited above provides insight into possible mechanisms associated with inhalational anthrax disease initiation and dissemination, one potential limitation in this body of work is that much of the research has been conducted in mice using attenuated strains of $B$. anthracis. Comparable detailed and mechanistic studies using larger animals like rabbits, where fully virulent spores are delivered via aerosols, are far more limited although some recent work describing natural history in the rabbit following aerosol exposure to Ames spores has been published (Lawrence et al., 2009; Yee et al., 2010). Clearly, the risk to laboratory personnel when aerosolizing fully virulent strains and the cost associated with larger animal BSL-3 aerosol studies are primary drivers in limiting the amount of work conducted to date in the rabbit. It should also be noted that additional advantages of working with mouse models compared to rabbits are that there is a far better understanding of the mouse immune system and there are considerably more reagents (such as antibodies) available for mouse studies than those for rabbits. However, if rabbit models of inhalational anthrax are considered appropriate for development and testing of therapeutics and the study of the end stages of inhalational anthrax disease (21 C.F.R. $\$ 314.610$, drugs; $\$ 601.91$, biologics), then additional work should be conducted that examines disease initiation and progression in this host.

The current work examined disease initiation and kinetics in the New Zealand white (NZW) rabbit model of inhalational anthrax following exposure to aerosols of fully virulent Ames spores. The mean time to death of rabbits has been reported at 2.4 days and the $\mathrm{LD}_{50}$ is estimated at $1.05 \times 10^{5}$ Ames spores (Zaucha et al., 1998; Fellows et al., 2001; Pitt et al., 2001; Phipps et al., 2004). Our experimental design consisted of exposing naïve animals to high (lethal, $>100 \mathrm{LD}_{50}$ ) doses of Ames aerosols and then quantifying the number of bacteria in different tissues as disease progressed. Bacteria were quantified from 0 to $36 \mathrm{~h}$ postexposure in the conducting airways, lung tissue, lymph nodes and circulation. A main experimental control for the infection in naive rabbits were rabbits challenged with the same aerosol dose but were also vaccinated with the human anthrax vaccine (Anthrax Vaccine Adsorbed, AVA). AVA is fully protective in NZW rabbits exposed to a lethal dose of Ames spores (Fellows et al., 2001; Pitt et al., 2001). By pairing non-vaccinated with AVAvaccinated rabbits during the exposures, host-pathogen responses that demonstrate vastly different outcomes in response to the same inhaled dose could be studied. Since the vaccine is fully protective in rabbits, vaccinated rabbits were able to completely clear all deposited spores, whereas in the non-vaccinated rabbit spores escaped from the immune system and entered an outgrowth phase leading to bacteremia and death.

\section{MATERIALS AND METHODS \\ B. anthracis AMES STRAIN}

Ames strain bacteria $\left(\mathrm{pXO}^{+}\right.$and $\left.\mathrm{pXO}^{+}\right)$were obtained from $\mathrm{C}$. Rick Lyons of the University of New Mexico. Spores were grown in trypticase soy broth supplemented with $100 \mathrm{mg} / \mathrm{L}$ manganese sulfate in a shaker incubator ( 225 revolutions per minute) at $37^{\circ} \mathrm{C}$ for approximately $96 \mathrm{~h}$. Spores were harvested by centrifugation, then re-suspended in sterile phosphate buffered saline (PBS), and stored at $4-6^{\circ} \mathrm{C}$. Spore were heat shocked at $65^{\circ} \mathrm{C} \pm 2^{\circ} \mathrm{C}$ immediately prior to use and the titer was determined before each exposure using standard dilution plating techniques (Turnbull et al., 2007).

\section{ANIMALS}

Certified Pasteurella-free male NZW rabbits were obtained from Covance Research Products (Denver, CO) and weighed between $2-4 \mathrm{~kg}$ at the time of aerosol exposures. Rabbits were fed Teklad Certified Global High Fiber Rabbit Diet (Harlan Teklad, Madison, WI), $150 \mathrm{~g}$, once daily and had unrestricted access to municipal water ad libitum. Controlled environmental conditions included temperature $\left(18-29^{\circ} \mathrm{C}\right)$, relative humidity $(30-70 \%)$ and light (12 $\mathrm{h}$ on and $12 \mathrm{~h}$ off). 


\section{VACCINATION}

Rabbits were vaccinated with an intramuscular injection of $0.5 \mathrm{ml}$ AVA (Biothrax ${ }^{\mathrm{TM}}$, Bioport Corporation, Lansing, MI; lot numbers FAV158, FAV114, FAV102 that was obtained through MILVAX) or were sham-vaccinated with an equal volume of PBS/2\% Alhydrogel (Sham). Alhydrogel was obtained from Brenntag Biosector (Frederikssund, Denmark). Injections occurred at week 0 (Day 0) and again at week 4 (Day 28) and the animals were challenged with aerosols of Ames spores at week 10 (day 70) (Fellows et al., 2001; Pitt et al., 2001). Most of the data presented in the current work were collected within $36 \mathrm{~h}$ following aerosol exposure. However, a portion of the rabbits were not sacrificed at the predetermined time point and were held for two weeks where AVA-vaccination proved $100 \%$ protective in all rabbits.

\section{BIOAEROSOL CHALLENGE WITH Bacillus anthracis AMES STRAIN}

Exposures occurred at the Lovelace Respiratory Research Institute, Albuquerque, MN. Rabbits were weighed and randomly assigned to exposure groups and subgroups using a computerized data acquisition system (Path-Tox 4.2.2; Xybion, Cedar Knolls, NJ). Body weights of individual animals did not exceed $\pm 20 \%$ of the groups mean. All data presented in the current work were generated from two sets of exposures. The first occurred during the months of September-December, 2006 and the second during the months of October, 2007 to January, 2008. Rabbits were placed into muzzle-only exposure boxes for 10, 30, and $45 \mathrm{~min}$ on three consecutive days prior to bioaerosol challenge for conditioning. Unless otherwise noted, all exposures lasted $16 \mathrm{~min}$ which was the exposure time required to reach the targeted presented dose given experimental setup. Rabbits sacrificed at $6,12,24$, or $36 \mathrm{~h}$ post-exposure were exposed in pairsone AVA-vaccinated paired with one sham-vaccinated rabbit. All rabbits were sacrificed using Euthasol or pentobarbital sodium. Rabbits sacrificed immediately following the end of the exposure were exposed one at a time and were exposed by alternating between one sham-vaccinated and one AVA-vaccinated animal. This allowed examination of each animal as soon as possible following the end of the exposure. The mean time required to decontaminate and remove a given animal from the exposure chamber to the beginning of euthanasia was $9.4 \pm 1.2 \mathrm{~min}$ and the mean time from start of euthanasia to necropsy was 10.2 $\pm 0.53 \mathrm{~min}$. Thus, the time from first inhaling a spore to the time of necropsy ranged from 30 to $45 \mathrm{~min}$ and are identified as $1 \mathrm{~h}$ in the Tables and Figures, or "without delay" or "immediately" in the text. Spores were aerosolized in PBS plus $0.01 \%$ Triton-X using a 3-jet collison nebulizer. The mean mass aerodynamic diameter of the spores was $1.0 \pm 0.3 \mu \mathrm{m}$ as measured using a TSI Aerosol Particle Sizer (TSI, Inc., Shoreview, MN). Aerosols were collected in all glass impingers (AGI) containing PBS $+0.01 \%$ Triton-X + antifoam. Aerosol dose was measured using a Buxco plethysmography system (Buxco Electronics, Wilmington, NC) on each animal. Animals were observed daily and moribund animals were euthanized immediately. In conducting this research, investigators adhered to the Guide for the Care and Use of Laboratory Animals [NIH publication 86-23, revised 1985].

\section{BACTERIAL QUANTIFICATION IN HOMOGENIZED LUNG TISSUE}

The bacterial load in the lung at a given time point was determined by dilution plate analysis of homogenized lung tissue. Here, immediately after sacrifice portions of the (non-lavaged) right middle lobe were excised, weighed $(0.440 \pm 0.001 \mathrm{~g}$, average weight), and homogenized in $50 \mathrm{ml}$ sterile PBS with $1 \%$ peptone at $4^{\circ} \mathrm{C}$ using a tissue homogenizer (Precision disposable tissue grinder system, VWR Scientific). Thereafter, an aliquot of the homogenate was plated on tryptic soy agar (TSA) plates (Hardy Diagnostics, Santa Maria, CA). The density of the lung homogenate $(0.999 \mathrm{~g} / \mathrm{ml})$ was used to convert colony forming unit/ml $(\mathrm{CFU} / \mathrm{ml})$ to $\mathrm{CFU} / \mathrm{gram}$ of lung tissue. In independent studies, the total average weight of the rabbit lung was determined from five non-treated, age- and weight-matched control animals. The mean mass was $17.00 \pm 2.4 \mathrm{~g}$ and was used to convert all CFU/gram tissue data to CFU/whole lung. Total CFU and spores were determined by plating a non-heated and heated aliquot of the homogenate, respectively. Unless otherwise noted, the difference between total CFU and spores represented the number of heat-sensitive vegetative bacteria.

\section{QUANTIFICATION OF BACTERIA AND ALVEOLAR MACROPHAGES IN BRONCHOALVEOLAR LAVAGE (BAL) FLUID}

The bacterial load in the conducting airways at a given time point post-exposure was a main data set we aimed to collect in this work and CFU were determined by dilution plate analysis of bronchoalveolar lavage (BAL) fluid. In addition to CFU in BAL, we also determined the number of macrophages in each BAL sample. The primary goal in collecting macrophage data was to help assess lavage efficiency in recovering deposited spores from all airways (discussed below), but these data are also useful in gaining better insight into the host immune response, and are also directly applicable to computational models of inhalational anthrax where alveolar macrophage numbers and function in the conducting airways pre- and post-exposure are key variables (Gutting et al., 2008; Day et al., 2011). Here, immediately after sacrifice the right lobes were clamped using a hemostat and the left three lobes were inflated two separate times with sterile saline $\left(4^{\circ} \mathrm{C}\right)$ using a syringe. The two individual BAL samples were then pooled into a single BAL sample per animal. Each BAL sample was weighed and a density of $1.001 \mathrm{~g} / \mathrm{ml}$ was used to calculate a total BAL volume. Prior to dilution plate analysis with or without heat kill $\left(65^{\circ} \mathrm{C}\right.$ for $\left.30 \mathrm{~min}\right)$, BAL samples were sonicated in an attempt to liberate any phagocytosed bacteria because there was concern that if a macrophage had engulfed multiple spores then this would be reflected as a single CFU on the TSA plate. Thus, the goal was to effectively destroy all macrophages in the BAL sample without affecting the viability of spores or vegetative bacteria when plated on TSA plates. A water bath sonicator was used (Misonix Sonicator 3000 Ultrasonic Liquid Processor, Misonix, Inc, Farmingdale, NY) set at 25\% amplitude for 3 min. Preliminary studies using either freshly isolated rabbit alveolar macrophages from non-treated animals, purified Ames spores, or freshly isolated Ames bacteria grown to log-phase, suggested that this treatment completely killed and disintegrated all macrophages while there was no observable effect on spore numbers and minimal effects on vegetative cells numbers. 
It was recognized that lavaging the airway two times was insufficient to wash out all the deposited spores. Therefore, a correction factor was needed to estimate the fraction of bacteria left in the airways following two lavages. This correction factor was determined by calculating the number of macrophages obtained from repeated lavages in control animals and then assuming the spores and macrophages can be lavaged with the same efficiency. Here, the left lobes from a group of five non-treated, age- and weight-matched rabbits were lavaged between two and eight times. The total number of alveolar macrophages recovered following two lavages was $8.02 \pm 3.02\left(\times 10^{6}\right)$. The number of recovered macrophages increased with more lavages and peaked at $21.22 \pm 5.98\left(\times 10^{6}\right)$ following eight lavages. Thus, there was a 2.645 fold difference in recovered macrophages following two or eight lavages and therefore the BAL bacterial data was adjusted by 2.645 .

Total bacterial numbers in the lower airways were calculated using the dilution series plate data, BAL density, the weight of the pooled BAL sample, a 2.65 correction factor, and finally a factor of two to reflect that only half the lung was lavaged.

Alveolar macrophages were determined using a hemacytometer. Trypan dye exclusion was used to determine viability. All cells with an approximate diameter of $15 \mu \mathrm{m}$ in the BAL samples were counted as an alveolar macrophage.

\section{BACTERIAL QUANTIFICATION IN LYMPH NODES AND BLOOD}

At the respective time point, tracheobronchial lymph nodes (TBLN) were removed and homogenized as described above for lung tissue. Due to their small size, the entire TBLN was homogenized in $5 \mathrm{ml}$ sterile PBS with $1 \%$ peptone at $4^{\circ} \mathrm{C}$ using a tissue homogenizer (Precision disposable tissue grinder system, VWR Scientific). CFU/lymph node was determined using homogenate weight, density, and plate counts. For analysis of blood, an aliquot of whole blood was collected using EDTA tubes and plated. A conversion factor of $56 \mathrm{ml}$ blood/ $\mathrm{kg}$ body weight was used to convert $\mathrm{CFU} / \mathrm{ml}$ blood to total CFU counts in the circulation.

\section{STATISTICAL ANALYSIS}

Unless otherwise stated, all data presented here are mean standard error of the mean (SEM). Student's $t$ test was used for pair-wise comparisons.

\section{RESULTS}

\section{PRESENTED DOSE OF AMES SPORES}

AVA- or sham-vaccinated NZW rabbits were exposed to heatshocked Ames spores $\left(65^{\circ} \mathrm{C} \pm 2^{\circ}, 30 \mathrm{~min}\right)$. As shown in Table 1, the mean presented dose of viable Ames spores was $44.28 \pm 5.7$ $\left(\times 10^{6}\right) \mathrm{CFU}$, which corresponded to an average dose of $422 \mathrm{LD}_{50}$. These data were collected by dilution plating aliquots (without heat treatment) from the AGIs. In addition, AGI aliquots were also treated at $65^{\circ} \mathrm{C} \pm 2^{\circ}$ for $30 \mathrm{~min}$ prior to plating. Here, the number of heat-resistant spores dropped approximately $30 \%$ to $28.51 \pm 3.3\left(\times 10^{6}\right) \mathrm{CFU}$ (Table 1). Because the spores were heatshocked prior to aerosolization, these data suggested approximately $30 \%$ of the aerosolized spores remained viable when plated on TSA plates, but were damaged sufficiently from the shearing forces placed on them during the aerosolization process that
Table 1 | Presented dose of Ames spores.

\begin{tabular}{lll}
\hline & \multicolumn{2}{c}{ Presented dose } \\
\cline { 2 - 3 } & $\left(\times \mathbf{1 0}^{\mathbf{6}}\right)$ & $\mathbf{L D}_{\mathbf{5 0}}$ \\
\hline Total spores & $44.28 \pm 5.7$ & $422 \pm 54$ \\
Heat resistant spores & $28.51 \pm 3.3$ & $271 \pm 32$ \\
Heat sensitive spores & $15.77 \pm 3.5$ & $150 \pm 33$ \\
$\%$ Inhaled heat resistant spores $(\times 100)$ & $69.30 \pm 2.7 \%$ & \\
$\%$ Inhaled heat sensitive spores $(\times 100)$ & $30.70 \pm 2.7 \%$ & \\
\hline
\end{tabular}

All values are mean \pm SEM $(n=60)$ and are data pooled from six separate exposure days where 10 rabbits were exposed each day.

they lost their heat-resistance. Thus, the average presented dose was $44.28 \pm 5.7\left(\times 10^{6}\right) \mathrm{CFU}$, of which approximately $70 \%$ of the spores were healthy and approximately $30 \%$ were damaged (Table 1). It is unclear how damaged heat-sensitive spores behave following deposition in relation to healthy heat-resistant spores, but one conclusion that can be reached using this data is that the detection of heat-sensitive CFU using standard dilution plate analysis in the airways (from BAL) or the lung tissue homogenate does not necessarily reflect in situ germination of newly deposited spores, particularly in samples collected immediately following exposure. Additional challenges in identifying germination in ex vivo tissue samples are discussed in more detail in the following sections (see below).

\section{LUNG DOSE (DEPOSITED DOSE) DETERMINED USING LUNG HOMOGENATES}

The lung tissue dose (deposited dose) was determined by enumeration of bacteria in homogenized lung tissue that was obtained immediately following exposure. As shown in Table 2, 10 rabbits were exposed to an average of $19.58 \pm 2.5\left(\times 10^{6}\right)$ total spores. The total number of viable bacteria recovered from homogenized lung tissue was $0.93 \pm 0.21\left(\times 10^{6}\right)$, which represented $4.63 \pm 1.1 \%$ of the presented dose. In an independent study that used 12 rabbits, $4.03 \pm 1.3 \%$ of the presented dose was recovered in homogenized lung tissue, which was not significantly different from the first study. Because approximately $30 \%$ of the inhaled spores were heat sensitive, it was not possible to assess spore germination in these samples using loss of heat resistance as the indicator of germination. Therefore, the data presented in Table 2 are total CFU recovered from lung homogenate. It is also worth noting that at no time point examined in the current work ( $0-36 \mathrm{~h}$ post-exposure) do we use loss of heat resistance as a measure of spore germination in lung tissue homogenates for this very reason. In addition, previous work by other investigators have also noted the challenges in detecting germination in homogenized tissue samples due to experimental artifacts that can skew results. These include, in part, loss of heat resistance resulting from the mechanical stresses placed on spores during homogenization, increased pressure, exposure to germinants from blood contaminants and/or the actual homogenization buffer introduced during tissue homogenization (the buffer used in the current studies contained peptone, a potential germinant), dose-effects where spore clumping or concentration 
Table 2 | Lung dose (deposited dose) determined by analysis of homogenized lung tissue.

\begin{tabular}{lrl}
\hline & $\left(\times \mathbf{1 0}^{\mathbf{6}}\right)^{\mathrm{a}}$ & \% Presented dose \\
\hline Presented dose & & \multicolumn{1}{c}{ b } \\
Total bacteria in homogenized & $0.93 \pm 0.2$ & $4.63 \pm 1.1 \% \%^{c}$ \\
Lung tissue & &
\end{tabular}

${ }^{a}$ Values are mean \pm SEM $(n=10)$.

${ }^{b}$ Total viable Ames spores inhaled during the exposure.

$c$ In an independent study, 12 rabbits inhaled $5.05 \pm 0.5\left(\times 10^{6}\right)$ Ames spores, where $4.03 \pm 1.3 \%$ were recovered in homogenized lung tissue immediately following exposure.

at certain areas of the airways can occur at high doses, and the method of euthanasia (Drysdale et al., 2005; Cote et al., 2006; Heninger et al., 2006; Glomski et al., 2008). Despite these potentially confounding issues in the germination state of bacteria in lung homogenates, there is no indication in the literature, to our knowledge, that bacteria can actually replicate during tissue processing (lungs were homogenized in ice cold homogenate immediately following necropsy). In summary, based on homogenizing lung tissue immediately following exposure, the total number of viable CFU recovered from the lung from two independent studies represented $4.03 \pm 1.3 \%$ and $4.63 \pm 1.1 \%$ of the presented dose.

\section{LUNG DOSE (DEPOSITED DOSE) DETERMINED FROM BAL}

The deposited dose was also determined by analysis of BAL fluid obtained immediately following exposure. These data are another method of determining deposition which can be compared to the deposition data obtained from lung tissue homogenates (see above) and also serve as the starting point for analyzing how fast bacteria are cleared from the airways over time following exposure (see below). As discussed above, no attempt was made to distinguish between dormant spores and germinated/germinating spores and the data are reported as total CFU in BAL. As shown in Table 3, 10 rabbits were exposed to an average of $19.58 \pm 2.5$ $\left(\times 10^{6}\right)$ total spores. Immediately following exposure the BAL was collected (two washes), sonicated, and plated on TSA plates. As shown, the total number of bacteria in the BAL was $0.25 \pm 0.07$ $\left(\times 10^{6}\right)$, which represented $1.16 \pm 0.03 \%$ of the presented dose. When adjusted by a factor of 2.65 (see Materials and Methods), these data suggested $3.07 \pm 0.9 \%$ of the presented dose was recovered from the conducting airways immediately following exposure. Although this value is lower than that determined by homogenizing lung tissue (i.e., $4.63 \pm 1.1 \%$ from Table 2), it was not significantly different from it $(p=0.285$ using a two tailed Student's $t$ test). In an independent study using 12 rabbits, $1.33 \pm$ $0.2 \%$ (mean \pm SEM) of the presented dose was recovered from the airways. The most likely reason for the consistently smaller CFU in BAL compared to lung homogenate is the inability to wash out all deposited spores regardless of the number of lavages, but another possible explanation is that some deposited spores may have already crossed the epithelial lining en route to the draining lymph nodes (see below) and are therefore not accessible using lavage.
Table 3 | Lung dose (deposited dose) determined by analysis of BAL fluid.

\begin{tabular}{lcl}
\hline & $\left(\times \mathbf{1 0}^{\mathbf{6}}\right)^{\mathrm{a}}$ & \% Presented dose \\
\hline Presented dose $^{\mathrm{b}}$ & $19.58 \pm 2.5$ & - \\
Total bacteria in sonicated & $0.25 \pm 0.07$ & $1.16 \pm 0.3 \%$ \\
BAL fluid (2 washes) & & \\
Total bacteria in sonicated & - & $3.07 \pm 0.9 \% \mathrm{e}$ \\
BAL fluid (adjusted) & & \\
\hline
\end{tabular}

a Values are mean \pm SEM $(n=10)$

${ }^{b}$ Total viable Ames spores inhaled during the exposure.

c Total recovered bacteria in BAL fluid obtained following 2 lavages.

${ }^{d}$ Total recovered bacteria in BAL fluid when adjusted by a factor of 2.65 (see Materials and Methods).

${ }^{e}$ In an independent study using 12 rabbits, $1.33 \pm 0.2 \%$ [adjusted] of the presented dose was recovered in BAL fluid.

\section{FATE OF DEPOSITED AMES SPORES AND KINETICS OF INFECTION}

The next objective was to determine the fate of the deposited spores in AVA-vaccinated and sham-vaccinated rabbits, and attempt to quantify the infection as it spread from the conducting airways to the circulation. Here, rabbits were sacrificed 6, 12, 24, and $36 \mathrm{~h}$ following exposure (by $36 \mathrm{~h}$, two sham-vaccinated rabbits had succumbed to infection- see Table 4). At the respective time point, tissues were collected and the bacterial load determined. There are several points are worth noting in the analysis that follows.

First, the number of bacteria present in the tissue at any given time point following exposure is a function of the number of deposited spores (i.e., a higher presented dose equals a higher deposited dose which, in turn, equals a higher initial tissue dose). For example, if $10^{5}$ total bacteria were detected in the lung tissue of a particular rabbit six h post-exposure, it is not possible to conclude if the total number of bacteria were increasing (suggesting an active infection) or decreasing without knowing how many were deposited at the start of the infection. In the analysis that follows, the number of bacteria deposited for each animal was calculated using each individual animals presented dose and the average deposited dose from Table 1 (i.e., 4.63\% of the individual presented dose).

Second, for clearance from the airways (BAL data), the data are presented as the percent remaining of the initial BAL dose for each animal. Percent remaining was used since the number of bacteria only decreased over time in this tissue compartment. However, for analysis of bacteria in lung tissue over time, where bacterial numbers decreased initially and then increased in some animals (due to germination and growth in situ or reseeding from the circulating bacteria, see below), and data are expressed as the percent change of deposited tissue dose.

\section{BACTERIAL CLEARANCE FROM THE AIRWAYS}

The number of bacteria in the airways over time was determined by dilution plate analysis of BAL using methods identical to that described above for the zero hour time point. Trypan blue negative (i.e., viable) alveolar macrophages in BAL were also quantified, which helped to enumerate bacteria by providing an 
Table 4 | Total bacteria in the tracheobronchial lymph nodes (TBLN) and blood ${ }^{a}$.

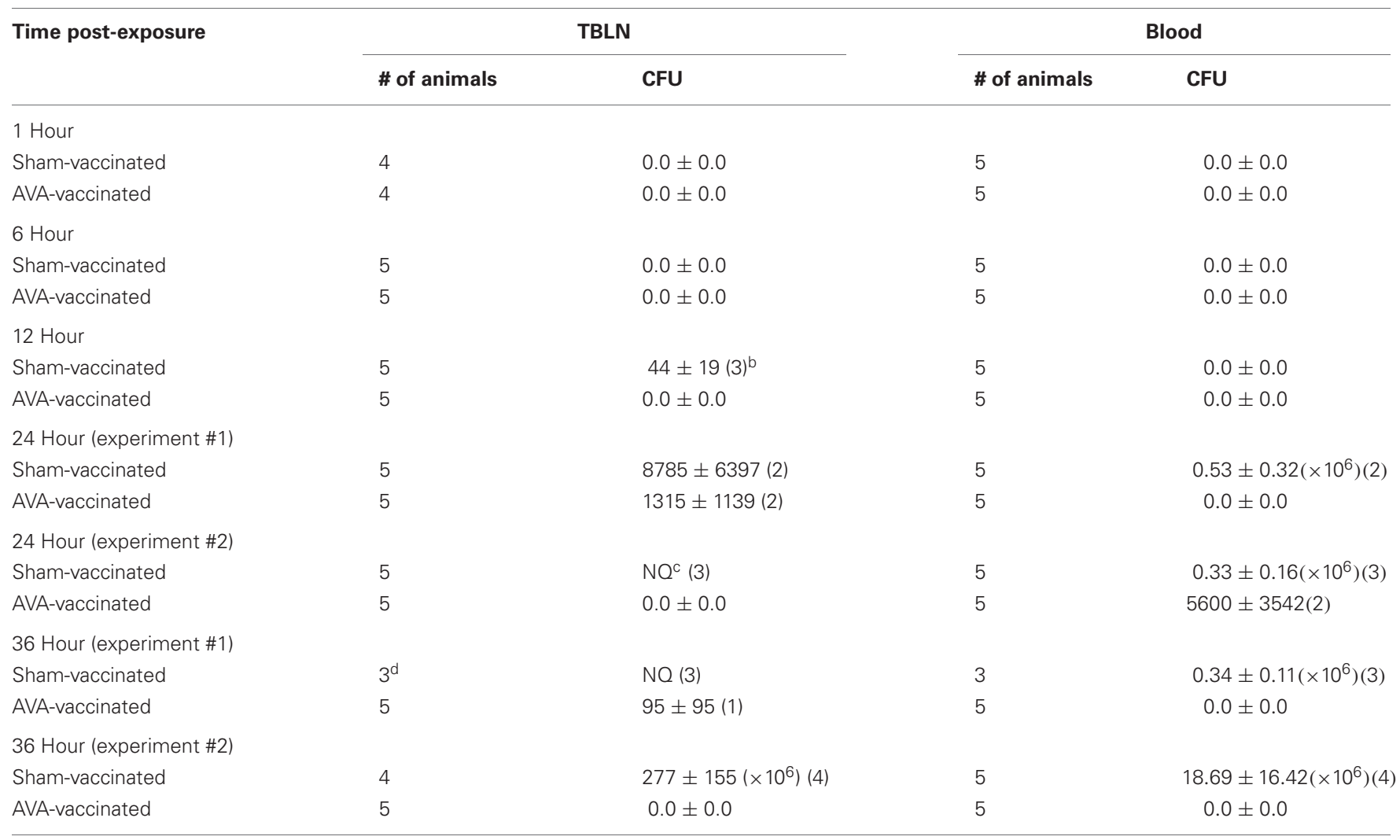

a Values are mean \pm SEM.

${ }^{b}$ Number in parenthesis are the number of animals testing positive (e.g., 3 of 5 sham-vaccinated animals had positive TBLNs at 12 h). However, for determining mean \pm SEM, all data were used (zero's were included in the calculation).

${ }^{c} N Q=$ not quantified; 3 of 5 lymph nodes were positive but bacteria were not quantified because plates were too numerous to count.

${ }^{d} 2$ of 5 animals died prior to $36 \mathrm{~h}$.

estimate of lavage efficiency and also provided potential information on the host immune response such as the spore/macrophage ratio in the airways over time. As shown in Figure 1, the number of total bacteria detected in BAL dropped steadily following exposure and by $36 \mathrm{~h}$ less than $5 \%$ of the initial dose was detected in BAL. As shown, $36 \mathrm{~h}$ following exposure $2.46 \pm 0.33 \%(n=8)$ and $4.28 \pm 2.06 \%(n=10)$ of the initial total bacterial dose remained detectable in BAL from sham-vaccinated and AVAvaccinated rabbits, respectively. Thus, there was no significant difference detected between sham-vaccinated and AVA-vaccinated rabbits in total CFU. In contrast, the numbers of macrophages from AVA-vaccinated rabbits remained unchanged through $36 \mathrm{~h}$, whereas BAL macrophage numbers from sham-vaccinated rabbits appeared to significantly decrease at the $24 \mathrm{~h}$ time point (Figure 1B).

\section{ENUMERATION OF BACTERIA (SPORES AND VEGETATIVE CELLS) IN LUNG TISSUE}

Attempts were made to quantify the number of heat-resistant and heat-sensitive bacteria in homogenized lung tissue over time. However, given the potential to render spores heat sensitive due to artifacts introduced during ex vivo tissue processing (discussed above), the main focus of these data are on the total number of heat-sensitive CFU at a particular time point relative to the number of total CFU deposited in the animal. If the total number of bacteria in the lung at a given time point exceeds the total number of bacteria deposited during the exposure, then germination and growth most likely has occurred at some point in the animal. The number of detectable spores (heat-resistant $\mathrm{CFU}$ ) in lung tissue steadily decreased over time in all animals with the most obvious decrease occurring within the first six hours of the infection (Figure 2A) and there was no difference in the number of spores between sham-vaccinated and AVA-vaccinated rabbits at any time point examined. Since the lungs were not lavaged prior to homogenization, these data include heat-resistant spores in the airways as well as any in lung tissue. These results suggest spores are efficiently removed from the lung tissue/airways and that vaccination has no observable effect.

With respect to heat-sensitive CFU, there were noticeable differences between vaccinated and non-vaccinated rabbits in the total number of heat-sensitive CFU over time in the lung. As shown in Figure 2B, there were no detectable changes in heatsensitive CFU from 0-36 $\mathrm{h}$ following exposure in AVA-vaccinated rabbits, suggesting there is no outgrowth of vegetative cells or reseeding of lung tissue from the small amounts of bacteria detected in the circulation during the time period (see Table 4). However, 


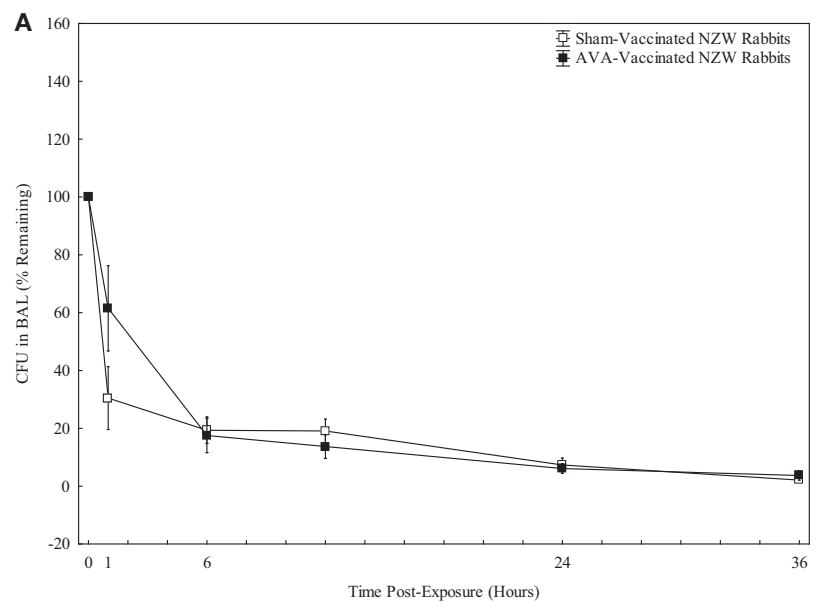

FIGURE 1 | Total bacteria (A) and macrophages (B) detected in

BAL fluid. Data were collected from sham-vaccinated $(\square)$ and AVA-vaccinated $(\square)$ rabbits immediately following exposure (1 h) and at $6,12,24$, and $36 \mathrm{~h}$ post-exposure. For (A), data were collected and pooled for the 1,6 , and $12 \mathrm{~h}$ time points from two separate experiments, and three separate experiments were used for the 24 and $36 \mathrm{~h}$ time points [ $n=8-16$ sham- or AVA-vaccinated rabbits per time point].

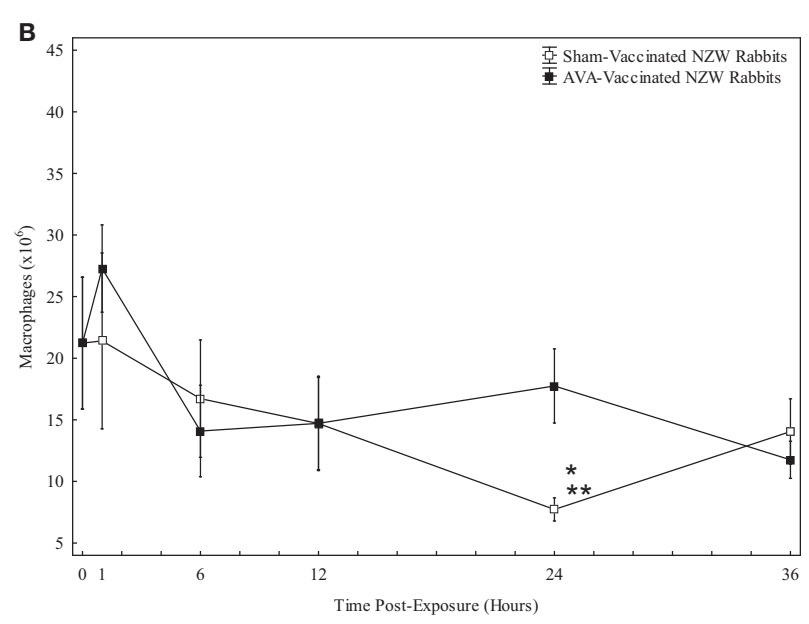

For (B), $n=5$ for the 1,6 , and $12 \mathrm{~h}$ groups and between 8-10 for the 24 and $36 \mathrm{~h}$ time points. Macrophage numbers at the zero time point are from five non-treated, age-matched and weight-matched control rabbits. All data are mean \pm SEM. In (B), at $24 \mathrm{~h}, \mathrm{BAL}$ from sham-vaccinated rabbits had significantly less macrophages: ${ }^{*} p=0.004$ compared to sham-vaccinated time zero animals and ${ }^{* *} p=0.005$ compared to AVA-vaccinated rabbits at the $24 \mathrm{~h}$ time point.

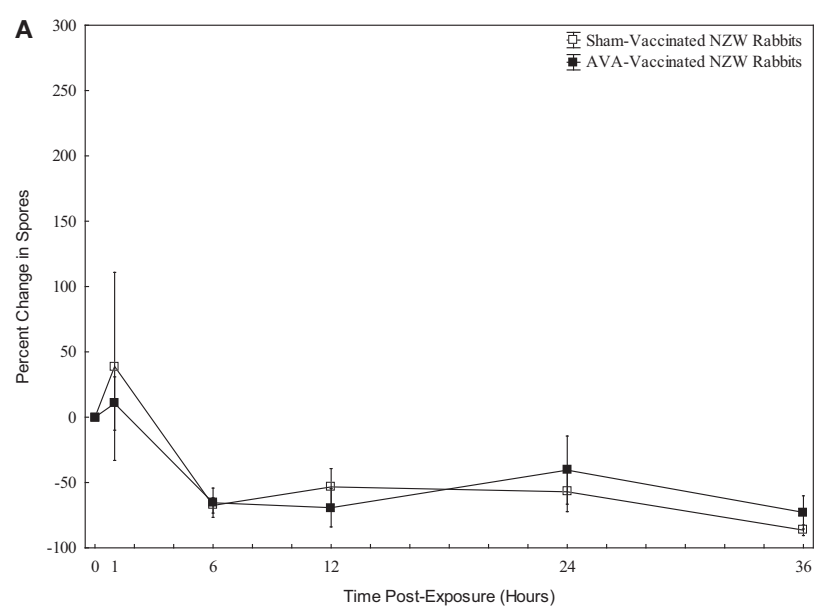

FIGURE 2 | Percent change in (A) spores and (B) vegetative bacteria in homogenized lung tissue from sham-vaccinated $(\square)$ and AVA-vaccinated (口) rabbits. Data were obtained immediately following exposure (1 h) and at $6,12,24$, and $36 \mathrm{~h}$ post-exposure. All data are expressed as a percent change

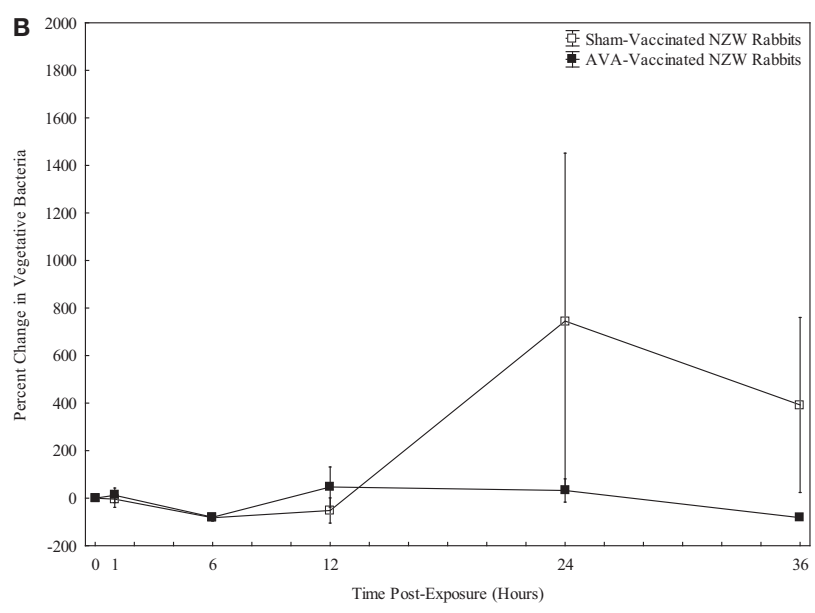

(increase or decrease) at a given time point relative to the initial lung tissue dose. All data are mean \pm SEM with five animals per group except for $36 \mathrm{~h}$ time point where data were pooled from two separate experiments ( $n=8-10$ animals). several sham-vaccinated rabbits showed dramatic increases in heat-sensitive CFU in lung tissue at 24 and $36 \mathrm{~h}$ such that the levels of bacteria in the lungs exceed the number of bacteria deposited during exposure. As shown in Figure 2B, $24 \mathrm{~h}$ following exposure the number of heat-sensitive CFU detected in the lung of the rabbits as a group increased by $745 \%$ and remained elevated through $36 \mathrm{~h}$ (approximately 370\%). Although there was a trend of increased heat-sensitive CFU in sham-vaccinated rabbits that was reproducible, there was no statistical significance $(p=0.17$, Student's $t$-test) between sham-vaccinated and AVA-vaccinated rabbits. It is also noted that the increased CFU in sham-vaccinated animals shown in Figure 2 did not occur in all animals and outliers are largely responsible the effects shown in Figure $\mathbf{2 B}$. The $24 \mathrm{~h}$ and $36 \mathrm{~h}$ data in Figure 2B for sham-vaccinated rabbits represents 13 rabbits and only six of them showed increases which ranged from $20 \%$ to greater than $3500 \%$. It is noted that using these data, it is not possible to determine if the increases in these six animals are due to in situ replication or re-seeding vegetative bacteria from circulating bacteria that is detected at these time points (Table 4). 


\section{BACTEREMIA IN THE TRACHEAL BRONCHIAL LYMPH NODES (TBLN) AND BLOOD}

The total number of bacteria in the TBLN and blood were determined (Table 4). Bacteria first appeared at $12 \mathrm{~h}$ in the TBLN from sham-vaccinated animals where CFU were detected in three of five animals ( $44 \pm 19 \mathrm{CFU})$. This number steadily increased through $36 \mathrm{~h}$ at which time lymph nodes from all animals were positive with nearly seven million CFU counted on average. In contrast, AVA-vaccinated rabbits had lower numbers of heatsensitive CFU in lymph nodes at $24 \mathrm{~h}(1315 \pm 1139 \mathrm{CFU})$ with even lower numbers detected at $36 \mathrm{~h}$ ( $31 \pm 106 \mathrm{CFU})$. CFU were first detected in the blood of both sham-vaccinated and AVAvaccinated rabbits at $24 \mathrm{~h}$. By $36 \mathrm{~h}$, all sham-vaccinated rabbits were bacteremic whereas no AVA-rabbits had detectable bacteria in the blood. As discussed above for lung homogenates [see "Lung Dose (Deposited Dose) Determined Using Lung Homogenates"], it is possible that some spores germinated ex vivo due to artifacts introduced during homogenization of the lymph nodes or handling of the blood samples. Thus, total CFU is the most reliable interpretation of the data, but it is worth noting that if spores were in the lymph or blood at the time of sacrifice and handling the respective sample ex vivo rendered the spores heat sensitive, then this artifact appears to affect nearly all spores in the sample because we could not detect heat sensitive CFU in the TBLN with any confidence and, to our knowledge, there are no published data available showing spores circulating in the blood 24-36 h following exposure in this model.

\section{DISCUSSION}

The objective of the current work was to characterize and quantify disease progression in the rabbit following inhalation of lethal doses of Ames spore aerosols. The initial aim was to determine what fraction of inhaled spores (presented dose) was deposited in the lung (tissue dose) during the exposure. Thereafter, the dissemination of bacteria from the lung to the draining lymph node and eventually to the circulation was quantified. Attempts were made to distinguish between spores and vegetative bacteria in some tissue compartments but as discussed throughout this paper, dilution plate data should be interpreted with caution due to the potential to introduce artifacts arising from ex vivo sample handling. Finally, side-by-side comparisons were made between naïve rabbits and rabbits that had been vaccinated with the human anthrax vaccine, which is known to provide complete protection in this experimental model. These observations are discussed below and we focus on how the data helps to expand our understanding of disease progression using this biological model, as well as how these data can support computational inhalational models for the rabbit and other species.

Analysis of lung homogenates from two separate studies (22 rabbits in total) suggested between $4.03-4.63 \%$ of the inhaled dose was deposited in the lung. Analysis of BAL fluid suggested slightly lower deposition (3.07\%) but the BAL data were not significantly different from homogenized lung data. To our knowledge, this is the first time deposition of $B$. anthracis spores has been examined in rabbits. Lower amounts in BAL are most likely due to the fact that not all deposited spores can be removed from the lung through lavage. These deposition data are in excellent agreement with our computational model of spore deposition in the rabbit (Gutting et al., 2008). Here, rabbit lung morphometry was coupled with the physical factors known to dictate particle flow and retention in the airways (such as spore size) to produce a model that predicted between $4-5 \%$ of the inhaled spore dose would be deposited in the rabbit lung. In spite of the data reproducibility shown in the current work and the correlation between these deposition data and preliminary computational model predictions, 4-5\% spore deposition is lower than the historical work that suggested between $15-20 \%$ of inhaled B. anthracis spores are retained in the lungs of laboratory animals (Barnes, 1947; Harper and Morton, 1953). There are many reasons that could explain this discrepancy. For example, Harper and Morton (1953) based their conclusions on radio labeled spores where it is probable that a large percentage of the radio-labeled ${ }^{32} \mathrm{P}$ recovered in the lung came from dead spores and/or spore debris. In contrast, the percent deposition presented in the current work is based on number of viable spores recovered from lung tissue homogenates. In the work of Barnes (1947), the percent deposition was based on average literature values for respiratory intake for a given species, whereas our work factored in individual animal breathing rates as measured real time during the exposures using plesthymography. It is also worth noting that in both of those historical studies, the authors did not detail the section of lung that was examined and it's possible that work examined some of the larger conducting airways which could account for higher deposition numbers. Furthermore, extraction efficiencies, differences in animal species, method of aerosolization, spore preparations, spore sizes, animal physiology (e.g., breathing frequency), and other factors could also contribute to the discrepancies between the historical deposition data and that presented in the current work. On a final note, in deriving the values presented in the current work we homogenized and plated a portion of the right middle lobe. These data were then multiplied by a factor of six to account for all six rabbit lobes. This approach assumed equal distribution throughout the entire lung and if other lobes retain a higher number of spores than the right middle lobe, then our calculations would be lower than the actual. Understanding spore deposition is critical to developing any computational model of inhalational anthrax (Weir and Haas, 2011); especially physiologically-based models of infection where crossspecies extrapolation is based on lung tissue dose (see Gutting et al., 2008 for review).

In addition to quantity, the current work also began to address the quality of inhaled spores. It is widely known that the physical forces placed on bacteria when converting them from liquid cultures to aerosols can be significant. Indeed, it is thought that B. anthracis was the first bacteria to be aerosolized in laboratory infection studies because it is a spore former and was therefore more likely to survive the shearing forces placed on it during the procedure (Buchner, 1888; Barnes, 1947; Harper and Morton, 1953). More recent work suggests as high as $50 \%$ of non-sporeforming microbes can be killed from the shearing forces placed on them during aerosolization (Mainelis et al., 2005). In the current work, heat-shocked Ames spores were aerosolized, collected in AGIs, and then re-examined for heat-resistance using 
dilution plate analysis. The data presented in Table 1 suggested approximately 3 of 10 spores recovered from the AGI were viable when spread on TSA plates, but were rendered non-viable following an additional heat treatment at $65^{\circ} \mathrm{C}$. It is reasonable to suggest that these spores were rendered heat sensitive primarily due to damage from the shearing forces placed on them during aerosolization, although other factors in the exposure system could also be contributing (such as Triton-X or antifoam). The most troubling aspect of delivering heat-sensitive damaged spores to the lung is that loss of heat-resistance is a hallmark of spore germination. Thus, assessing spore germination in BAL samples or homogenized lung tissue based on heat resistance in dilution plate assays was not possible. It is also not known how damaged spores interact with the host compared to undamaged spores (are they cleared faster, do they germinate at all?), but others have shown that modifying healthy spores by promoting or inhibiting germination prior to delivery to the airways can significantly affect disease outcome (McKevitt et al., 2007; Cote et al., 2009). We have examined other methods in an attempt to detect and quantify germination in the lung, such as PCR and microscopy (data not shown), and these are the subject of ongoing investigations.

Deposited bacteria were cleared quickly from the airways. Analysis of BAL samples over time revealed that approximately $80 \%$ of the spores were cleared from the conducting airways within six hours (Figure 1). Thereafter, viable bacterial numbers continue to decrease such that at $36 \mathrm{~h}$ post-exposure less than $4 \%$ of the deposited dose remains detectable in BAL samples. It is likely that a large portion of the deposited spores were cleared via the ciliated epithelium that extends throughout the respiratory tract down to the small bronchioles. This mechanism of clearance in mammals is exceptionally efficient (approaching $2 \mathrm{~cm} / \mathrm{min}$ ) and observations made by others using Bacillus subtilis suggested as much as $70 \%$ of the spores retained in the airways following inhalation are cleared through this mechanism (Harper and Morton, 1953). Another mechanism of B. anthracis spore clearance from the airways is through phagocytosis by alveolar macrophages with subsequent transport across the lung epithelium to the lymph nodes (Young et al., 1946; Barnes, 1947; GuidiRontani, 2002). In the current work, total bacteria appeared in the TBLN between 6-12 $\mathrm{h}$ following exposure in sham-vaccinated rabbits and between 12-24 h in AVA-vaccinated rabbits (Table 4). For naïve rabbits, this was well before any bacteria were detected in the circulation (Table 4). These data support the hypothesis that motile immune cells such as macrophages or dendritic cells are transporting a portion of the deposited bacteria from the airways to the lymph nodes, but do not prove that is occurring and if so, whether or not this is the only mechanism of dissemination. For additional support of the Trojan horse hypothesis, we also examined bacterial titers in BAL samples before and after the sample was sonicated and hypothesized that if alveolar macrophages were efficiently engulfing deposited spores then many macrophages would be carrying multiple spores. When spread on a TSA plate these engulfed spores would collectively form a single CFU. However, if the macrophage was destroyed (via sonication) prior to plating then the engulfed spores would disseminate in the sample and the CFU would increase. In the analysis, $77 \%$ of the BAL samples had more CFU post-sonication when directly compared to the same sample prior to sonication (data not shown). Qualitatively, microscopy of BAL also revealed spores associated with alveolar macrophages (data not shown). In summary, these data show deposited spores were quickly cleared from the airways and suggest a portion of them were associated with resident alveolar macrophages during this process. Clearance from the lung is the main parameter in the competing risks model of inhalational anthrax when examining dose-response and incubation period (Brookmeyer et al., 2005; Wilkening, 2006, 2008), as well as when modeling post-exposure antibiotic treatment or vaccination (Brookmeyer and Blades, 2002; Brookmeyer et al., 2003, 2004). However, all of that work is based off of data collected in a non-human primate model of inhalational anthrax. Therefore, it would be important to examine these models in a second species, such as the rabbit, and this ongoing in our lab.

A central question during disease progression is whether or not spore germination occurs in the lung tissue during transport from the airways to the lymph nodes and if so, do a portion of the newly germinated spores escape the immune system and enter extracellular outgrowth in the lung tissue. Or, in contrast, do spores germinate and escape only after arriving in the lymph node. Historical studies that used virulent strains of $B$. anthracis suggested the lung was not conducive to germination and that most, if not all, germination and escape occurred once the spores arrived in the draining lymph nodes (Henderson et al., 1956; Brachman et al., 1966; Grinberg et al., 2001). However, more recent studies using attenuated strains suggested germination occurred in lung tissue (Lyons et al., 2004; Glomski et al., 2007; Sanz et al., 2008). Determining when and where germination is occurring in the rabbit-Ames aerosol model has proved equally challenging for two main reasons. First, the time point at which some animals show dramatic increases in lung CFU (higher than the total number of CFU deposited in the lung) is a time that is also associated with detection of circulating bacteria ( $24 \mathrm{~h}$ : Figure 2, Table 4). It is therefore possible that the increases in the lung are due to re-seeding from the circulation and not outgrowth during transport from the airways to the lymph nodes. Second, as discussed previously, inhalation of heat-sensitive damaged spores, in addition to ex vivo processing that can render spores heat sensitive, make interpretation of dilution plate data pre- and postheat kill near impossible. Although ultimately inconclusive when defining the state of the spore, these data are still valuable when viewed as total CFU in the lung over time with respect to characterizing therapeutic windows and modeling the general infection process.

As disease progressed in sham-vaccinated rabbits, heatsensitive CFU were detected in the tracheal bronchial lymph nodes (TBLNs) $12 \mathrm{~h}$ following inhalation and then in the blood by $24 \mathrm{~h}$ (Table 4 ). Total bacterial numbers continued to increase in both TBLNs and blood through $36 \mathrm{~h}$ at which point in time 2 of 10 sham-vaccinated rabbits had died. These data support the hypothesis that dissemination following inhalation is from the lung through the lymph nodes to the circulation. The data agree with the work of Hughes et al. (1956) who showed using inhaled M36 strain B. anthracis spores that cannulation and blockage 
of the rabbit lymphatics delayed disease onset but did not prevent it completely. These data are also in good agreement with Barnes (1947), who used a virulent strain of B. anthracis to show replicating bacteria in TBLNs $24 \mathrm{~h}$ following inhalation and Ross (1957), who concluded spores ingested by phagocytic cells are carried to the TBLNs where they proliferated. Finally, these data also agree with the data published by Kobiler et al. (2006), who showed bacteremia in the blood of rabbits 18-90 h following intranasal installation of Vollum spores and Yee et al. (2010) who showed bacteremia in rabbits following inhalation of Ames spores $23.1 \pm 0.2 \mathrm{~h}$. Although the present work cannot rule out passage of bacteria from the lung or the lymph node directly into the circulation, the data does suggest if bacteria enter the blood via these more direct routes it is occurring about the same time as passage from the lymph to the blood.

The main use of AVA in this work was as an experimental control to aid in the interpretation of data collected from shamvaccinated (naïve) rabbits. By pairing sham-vaccinated rabbits side-by-side with AVA-vaccinated rabbits, we were able to study host-pathogen interactions in groups of rabbits that demonstrate vastly different outcomes when presented with the same inhaled dose of spores. However, the data collected may also be useful for investigators studying the protective mechanisms associated with AVA vaccination and in particular, the combination of vaccination and post-exposure antibiotic treatment. The predominant effect of vaccination with AVA is production of anti-protective antigen (PA) antibodies and the level of anti$\mathrm{PA}$ at the time of spore challenge is correlated with the level of protection in the rabbit (Fellows et al., 2001; Pitt et al., 2001). The mechanism of protection likely involves toxin neutralization (Brachman and Friedlander, 1999), which when neutralized from toxin-producing bacteria, would give the host a significant advantage in clearing the invading bacteria. The data presented here suggest vaccinated rabbits had a systemic infection because heat-sensitive CFU were detected in the lymph node (24-36 h post-exposure) and circulation ( $24 \mathrm{~h}$ only) following aerosol exposure to spores. In both the lymph nodes and blood, the level of vegetative bacteria appeared to peak $24 \mathrm{~h}$ following exposure. These data may aid investigators in defining a therapeutic window based on vegetative bacteria in specific tissue compartments.

As discussed previously, the main objective of the data collected in the current work is for use in developing computational models of anthrax to better understand disease, aid in drug development, and contribute to developing human risk assessments (reviewed in Gutting et al., 2008). There are several preliminary models inhalational anthrax models published to date that examine systemic disease (Kumar et al., 2008; Day et al., 2011). Information relating to bacterial numbers in specific tissues, germination, and kinetics presented in the current work may be useful in defining parameter values in these types of deterministic models. Additionally, the bacterial clearance rate from the lung of the rabbit as well as other information presented here has direct application in the competing risks stochastic model of inhalational anthrax that has been developed for man using nonhuman primate data (Brookmeyer et al., 2003, 2005; Wilkening, 2008).

In summary, the current work quantified the deposition and dissemination of fully virulent Ames spores in naïve and AVAvaccinated rabbits following aerosol exposure of lethal doses. The data suggested there was a systemic infection in both groups as bacteria were detected $24 \mathrm{~h}$ following exposure in the circulation. In vaccinated rabbits the numbers of bacteria were low and transient. In contrast, naïve rabbits demonstrated increasing bacterial numbers over time in the lung tissue, lymph node, and the circulation. These data may be useful in advancing our understanding of inhalational anthrax, defining therapeutic windows and developing computational models of disease for use in human risk assessments.

\section{FUNDING}

This work was supported by the Environmental Protection Agency (DW17922155-01-1) and the Defense Threat Reduction Agency (BA06TAS022).

\section{REFERENCES}

Barnes, J. M. (1947). The development of anthrax following the administration of spores by inhalation. $B r$. J. Exp. Pathol. 28, 385-394.

Brachman, P. S., and Friedlander, A. M. (1999). "Anthrax," in Vaccines, 3rd Edn. eds S. A. Plotkin and W. A. Orenstein (Philadelphia, PA: W. B. Saunders), 629-637.

Brachman, P. S., Kaufman, A. F., and Dalldorf, F. G. (1966). Industrial inhalation anthrax. Bacteriol. Rev. 30, 646-659.

Brachman, P. S., Plotkin, S. A., Bumford, F. H., and Atchison, M. M. (1960). An epidemic of inhalation anthrax: the first in the twentieth century. II. Epidemiology. Am. J. Hyg. 72, 6-23.
Brookmeyer, R., and Blades, N. (2002). Prevention of inhalation anthrax in the US outbreak. Science 295, 1861.

Brookmeyer, R., Johnson, E., and Barry, S. (2005). Modelling the incubation period of anthrax. Stat. Med. 28, 531-542.

Brookmeyer, R., Johnson, E., and Bollinger, R. (2003). Modeling the optimum duration of antibiotic prophylaxis in an anthrax outbreak. Proc. Nat. Acad. Sci. U.S.A. 100, 10129-10132.

Brookmeyer, R., Johnson, E., and Bollinger, R. (2004). Public health vaccination policies for containing an anthrax outbreak. Nature 432, 901-904.

Buchner, S. (1888). Untersuchungen über den Durchtritt von Infection serregern durch die Intacte Lungenoberflache. J. Hyg. (Berl.) 8, 145-245.

Canter, D. A. (2005). Addressing residual risk issues at anthrax cleanups: how clean is safe? J. Toxicol. Environ. Health A 68, 1017-1032.

Cleret, A., Quesnel-Hellmann, A., Vallon-Eberhard, A., Verrier, B., Jung, S., Vidal, D., Mathieu, J., and Tournier, J.-N. (2007). Lung dendritic cells rapidly mediate anthrax spore entry through the pulmonary route. J. Immunol. 178, 7994-8001.

Cote, C. K., Bozue, J., Twenhafel, N., and Welkos, S. L. (2009). Effects of altering the germination potential of Bacillus anthracis spores by exogenous means in a mouse model. J. Med. Microbiol. 58, 816-825.
Cote, C. K., Rooijen, N. V., and Welkos, S. L. (2006). Roles of macrophages and neutrophils in the early host response to Bacillus anthracis spores in a mouse model of infection. Infect. Immun. 74, 469-480.

Day, J., Friedman, A., and Schlesinger, L. S. (2011). Modeling the host response to inhalation anthrax. J. Theor. Biol. 276, 199-208.

Dewan, P. K., Fry, A. M., Laserson, K., Tierney, B. C., Quinn, C. P., Hyaslett, J. A., Siegel, L., Hales, T., Semenova, V. A., Tomero-Steiner, S., Elie, C., Khabbaz, R., Khan, A. S., Hajjeh, R. A., Schuchat, A., and members of the Washington D.C. anthrax response team. (2002). Inhalational anthrax outbreak 
among postal workers, Washington, D.C., 2001. Emerg. Infect. Dis. 8, 1066-1072.

Dixon, T. C., Meselson, M., Guillemin, J., and Hanna, P. C. (1999). Anthrax. N. Engl. J. Med. 341, 815-826.

Drysdale, M., Heninger, S., Hutt, J., Chen, Y., Lyons, C. R., and Koehler, T. M. (2005). Capsule synthesis by Bacillus anthracis is required for dissemination in murine inhalation anthrax. EMBO J. 24, 221-227.

Fellows, P. F., Linscott, M. K., Ivins, B. E., Pitt, M. L., Rossi, C. A., Gibbs, P. H., and Friedlander, A. M. (2001). Efficacy of a human anthrax vaccine in guinea pigs, rabbits, and rhesus macaques against challenge by Bacillus anthracis isolates of diverse geographical origin. Vaccine 19, 3241-3247.

Frazier, A. A., Franks, T. J., and Galvin, J. R. (2006). Inhalational anthrax. J. Thorac. Imaging 21, 252-258.

Glomski, I. J., Dumetz, R., Jouvion, G., Huerre, M. R., Mock, M., and Goossens, P. L. (2008). Inhaled nonincapsulated Bacillus anthracis in $\mathrm{A} / \mathrm{J}$ mice: nasopharynx and alveolar space as dual portals of entry, delayed dissemination, and specific organ targeting. Microbes Infect. 10, 1398-1404.

Glomski, I. J., Piris-Gimenez, A., Huerre, M., Mock, M., and Goossens, P. L. (2007). Primary involvement of pharynx and Peyer's patch in inhalational and intestinal anthrax. PLoS Pathog. 3:699-708. doi: 10.1371/journal.ppat.0030076

Grinberg, L. M., Abramova, F. A., Yampolskaya, O. V., Walker, D. H., and Smith, J. H. (2001). Quantitative pathology of inhalational anthrax I: quantitative microscopic findings. Mod. Pathol. $14,482-495$

Guidi-Rontani, C. (2002). The alveolar macrophage: the Trojan horse of Bacillus anthracis. Trends Microbiol. 10, 405-409.

Guidi-Rontani, C., Weber-Levy, M., Labruyere, E., and Mock, M. (1999). Germination of Bacillus anthracis spores within alveolar macrophages. Mol. Microbiol. 31, 9-17.

Gutting, B. W., Channel, S. R., Berger, A. E., Gearhart, J. M., Andrews, G. A., Sherwood, R. L., and Nichols, T. L. (2008). Mathematically modeling inhalational anthrax. Microbe 3, 78-85.

Hambleton, P., Carman, J. A., and Melling, J. (1994). Anthrax: the disease in relation to vaccines. Vaccine $2,125-132$.

Harper, G. J., and Morton, J. D. (1953). The respiratory retention of bacterial aerosols: experiments with radioactive spores. J. Hyg. (Lond.) 51, 372-385.

Henderson, D. W., Peacock, S., and Belton, F. C. (1956). Observations on the prophylaxis of experimental pulmonary anthrax in the monkey. J. Hyg. (Lond.) 54, 28-36.

Heninger, S., Drysdale, M., Lovchik, J., Hutt, J., Lipscomb, M. F., Koehler, T. M., and Lyons, C. R. (2006). Toxin-deficient mutants of Bacillus anthracis are lethal in a murine model for pulmonary anthrax. Infect. Immun. 74, 6067-6074.

Holtz, T. H., Ackelsberg, J., Kool, J. L., Rosselli, R., Marfin, A., Matte, T., Beatrice, S. T., Heller, M. B., Hewett, D., Moskin, L., Bunning, M. L., Layton, M., and the New York City anthrax investigation working group. (2003). Isolated case of bioterrorism-related inhalational anthrax, New York City, 2001. Emerg. Infect. Dis. 9, 689-696.

Hughes, R., May, A. J., and Widdicombe, J. G. (1956). The role of the lymphatic system in the pathogenesis of anthrax. Br. J. Exp. Pathol. 37, 343-349.

Inglesby, T. V., Henderson, D. A., Bartlett, J. G., Ascher, M. S., Eitzen, E., Friedlander, A. M., Hauer, J., McDade, J., Osterholm, M. T., O’Toole, T., Parker, G., Perl, T. M., Russell, P. K., and Tonat, K. (1999). Anthrax as a biological weapon: medical and public health management. Working Group on Civilian Biodefense. JAMA 281, 1735-1745.

Inglesby, T. V., O’Toole, T., Henderson, D. A., Bartlett, J. G., Ascher, M. S., Eitzen, E., Friedlander, A. M., Gerberding, J., Hauer, J., Hughes, J., McDade, J., Osterholm, M. T., Parker, G., Perl, T. M., Russell, P. K., and Tonat, K. (2002). Anthrax as a biological weapon, 2002: updated recommendations for management. JAMA 287, 2236-2252.

Ireland, J. A., and Hanna, P. C. (2002). Macrophage-enhanced germination of Bacillus anthracis endospores requires gerS. Infect. Immun. 70, 5870-5872.

Jernigan, D. B., Raghunathan, P. L., Bell, B. P., Brechner, R., Bresnitz, E. A., Butler, J. C., Cetron, M., Cohen, M., Doyle, T., Fischer, M., Greene, C., Griffith, K. S., Guarner, J., Hadler, J. L., Hayslett, J. A., Meyer, R., Petersen, L. R., Phillips, M., Pinner, R., Popovic, T., Quinn, C. P., Reefhuis, J., Reissman, D., Rosenstein, N., Schuchat, A., Shieh,W.-J., Siegal, L., Swerdlow, D. L., Tenover, F. C., Traeger, M., Ward, J. W., Weisfuse, I., Wiersma, S., Yeskey, K., Zaki, S., Ashford, D. A., Perkins, B. A.,
Ostroff, S., Hughes, J. M., Fleming, D., Koplan, J. P., Gerberding, J. L., and the National Anthrax Epidemiologic Investigation Team. (2002). Investigation of bioterrorism-related anthrax, United States, 2001: epidemiologic findings. Emerg. Infect. Dis. 8, 1019-1028.

Kobiler, D., Weiss, S., Levy, H., Fisher, M., Mechaly, A., Pass, A., and Altboum, Z. (2006). Protective antigen as a correlative marker for anthrax in animal models. Infect. Immun. 74, 5871-5876.

Kumar, R., Chow, C. C., Bartels, J. D., Clermont, G., and Vodovotz, Y. (2008). A mathematical simulation of the inflammatory response to anthrax infection. Shock 29, 104-111.

Lawrence, W. S., Hardcastle, J. M., Brining, D. L., Weaver, L. E., Ponce, C., Whorton, E. B., and Peterson, J. W. (2009). The physiologic responses of Dutch belted rabbits infected with inhalational anthrax. Comp. Med. 59, 257-265.

Loving, C. L., Khurana, T., Osorio, M., Lee, G. M., Kelly, V. K., Stilitz, S., and Merkel, T. J. (2009). Role of anthrax toxins in dissemination, disease progression, and induction of protective adaptive immunity in the mouse aerosol challenge model. Infect. Immun. 77, 255-265.

Lyons, C. R., Lovchik, J., Hutt, J., Lipscomb, M. F., Wang, E., Heninger, S., Berliba, L., and Garrison, K. (2004). Murine model of pulmonary anthrax: kinetics of dissemination, histopathology, and mouse strain susceptibility. Infect. Immun. 72, 4801-4809.

Mainelis, G., Berry, D., An, H. R., Yao, M., DeVoe, K., Fennell, D. E., and Jaegar, R. (2005). Design and performance of a single-pass bubbling bioaerosol generator. Atmos. Environ. 39, 3521-3533.

McKevitt, M. T., Bryant, K. M., Shakir, S. M., Larabee, J. L., Blanke, S. R., Lovchik, J., Lyons, C. R., and Ballard, J. D. (2007). Effects of endogenous D-alanine synthesis and autoinhibition of Bacillus anthracis germination on in vitro and in vivo infections. Infect. Immun. 12, 5726-5734.

Mock, M., and Fouet, A. (2001). Anthrax. Annu. Rev. Microbiol. 55, 647-671.

Phipps, A. J., Premanandan, C., Barnewall, R. E., and Lairmore, M. D. (2004). Rabbit and nonhuman primate models of toxin-targeting human anthrax vaccines. Microbiol. Mol. Biol. Rev. 68, 617-629.
Pitt, M. L., Little, S. F., Ivins, B. E., Fellows, P., Barth, J., Hewetson, J., Gibbs, P., Dertzbaugh, M., and Friedlander, A. M. (2001). In vitro correlate of immunity in a rabbit model of inhalational anthrax. Vaccine 19, 4768-4773.

Ross, J. M. (1957). The pathogenesis of anthrax following the administration of spores by the respiratory route. J. Pathol. Bacteriol. 73, 485-494.

Sanz, P., Teel, L. D., Alem, F., Carvalho, H. M., Darnell, S. C., and O'Brien, A. D. (2008). Detection of Bacillus anthracis spore germination in vivo by bioluminescence imaging. Infect. Immun. 76, 1036-1047.

Shetron-Rama, L. M., Herring-Palmer, A. C., Huffnagle, G. B., and Hanna, P. (2010). Transport of Bacillus anthracis from the lungs to the draining lymph nodes is a raid process facilitated by CD1lct cells. Microb. Pathog. 49, 38-46.

Turnbull, P. C., Frawley, D. A., and Bull, R. L. (2007). Heat activation/shock temperatures for Bacillus anthracis spores and the issue of spore plate counts versus true numbers of spores. J. Microbiol. Methods $68,353-357$.

Watson, A., and Keir, D. (1994). Information on which to base assessments of risk from environments contaminated with anthrax spores. Epidemiol. Infect. 113, 479-490.

Weiner, Z. P., and Glomski, I. J. (2012). Updating perspectives on the initiation of Bacillus anthracis growth and dissemination through its host. Infect. Immun. 80, 1626-1633.

Weir, M. H., and Haas, C. N. (2011). A model for in vivo delivered dose estimation for inhaled Bacillus anthracis spores in humans with interspecies extrapolation. Environ. Sci. Technol. 45, 5828-5833.

Wilkening, D. A. (2006). Sverdlovsk revisited: modeling human inhalation anthrax. Proc. Natl. Acad. Sci. U.S.A. 103, 7589-7594.

Wilkening, D. A. (2008). Modeling the incubation period of inhalational anthrax. Med. Decis. Making 28, 593-605.

Yee, S. B., Hatkin, J. M., Dyer, D. N., Orr, S. A., and Pitt, M. L. (2010). Aerosolized Bacillus anthracis infection in New Zealand white rabbits: natural history and intravenous levofloxacin treatment. Comp. Med. 60, $461-468$.

Young, G. A. Jr., Zelle, M. R., and Lincoln, R. E. (1946). Respiratory pathogenicity of 
Bacillus anthracis spores. I. Methods of study and observation on pathogenesis. J. Infect. Dis. 79, 233-246.

Zaucha, G. M., Pitt, L. M., Estep, J., Ivins, B. E., and Friedlander, A. M. (1998). The pathology of experimental anthrax in rabbits exposed by inhalation and subcutaneous inoculation. Arch. Pathol. Lab. Med. 122, 982-992.
Conflict of Interest Statement: The authors declare that the research was conducted in the absence of any commercial or financial relationships that could be construed as a potential conflict of interest.

Received: 30 March 2012; accepted: 06 June 2012; published online: 28 June 2012.
Citation: Gutting BW, Nichols TL, Channel SR, Gearhart JM, Andrews GA, Berger AE, Mackie RS, Watson BJ, Taft SC, Overheim KA and Sherwood $R L$ (2012) Inhalational anthrax (Ames aerosol) in naïve and vaccinated New Zealand rabbits: characterizing the spread of bacteria from lung deposition to bacteremia. Front. Cell. Inf. Microbio. 2:87. doi: 10.3389/fcimb. 2012.00087
Copyright (C) 2012 Gutting, Nichols, Channel, Gearhart, Andrews, Berger, Mackie, Watson, Taft, Overheim and Sherwood. This is an open-access article distributed under the terms of the Creative Commons Attribution Non Commercial License, which permits non-commercial use, distribution, and reproduction in other forums, provided the original authors and source are credited. 